\title{
Pattern of local recurrence after mastectomy and reconstruction in breast cancer patients: a systematic review
}

\author{
Ji Hyeon Joo^, Yongkan $\mathrm{Ki}^{2}$, Wontaek Kim², Jiho Nam$^{3}$, Donghyun Kim², Jongmoo Park ${ }^{4}$, \\ Hyun Yul Kim ${ }^{5}$, Youn Joo Jung ${ }^{5}$, Ki Seok Choo ${ }^{6}$, Kyung Jin Nam ${ }^{6}$, Su Bong Nam ${ }^{7}$ \\ ${ }^{1}$ Department of Radiation Oncology, Pusan National University Yangsan Hospital, Yangsan, Korea; ${ }^{2}$ Department of Radiation Oncology, Pusan \\ National University School of Medicine, Yangsan, Korea; ${ }^{3}$ Department of Radiation Oncology, Pusan National University Hospital, Busan, \\ Korea; ${ }^{4}$ Department of Radiation Oncology, Kyungbook National University Chilgok Hospital, Daegu, Korea; ${ }^{5}$ Department of Surgery, Pusan \\ National University Yangsan Hospital, Yangsan, Korea; ${ }^{6}$ Department of Radiology, Pusan National University School of Medicine, Yangsan, Korea; \\ ${ }^{7}$ Department of Plastic and Reconstructive Surgery, Pusan National University School of Medicine, Yangsan, Korea \\ Contributions: (I) Conception and design: JH Joo, SB Nam; (II) Administrative support: Y Ki, Wo Kim, J Nam, D Kim; (III) Provision of study \\ materials or patients: HY Kim, YJ Jung; (IV) Collection and assembly of data: KS Choo, KJ Nam; (V) Data analysis and interpretation: JH Joo, J \\ Park; (VI) Manuscript writing: All authors; (VII) Final approval of manuscript: All authors. \\ Correspondence to: Su Bong Nam, MD, PhD. Department of Plastic and Reconstructive Surgery, Pusan National University Yangsan Hospital, Pusan \\ National University School of Medicine, 20 Geumo-ro, Mulgeumeup, Yangsan 50612, Korea. Email: subong71@hanmail.net.
}

Background This study aimed to describe the locations of local recurrences based on the mastectomy and reconstruction type in breast cancer patients.

Methods: In November 2020, a systematic literature review was performed through MEDLINE/PubMed and the Cochrane Centre Register of Controlled Trials. Publications that included skin-sparing or nipplesparing mastectomy followed by breast reconstruction and described the location of local recurrences were analyzed. Exclusion criteria included salvage or prophylactic mastectomy, unclear distinction between local and regional recurrences, rare tumor types.

Results: From 19 publications, 272 local recurrences lesions were reported in a total of 4,787 patients. After autologous reconstruction $(n=2,465)$, local recurrences were located in the skin in $45(1.8 \%)$ patients, in the chest wall in 18 (0.7\%), and in the nipple-areolar complex in $9(0.4 \%)$. After implant reconstruction $(\mathrm{n}=1,917)$, local recurrences sites included the skin in $91(4.7 \%)$ patients, chest wall in $8(0.4 \%)$, and nippleareolar complex in $8(0.4 \%)$. Of the 70 lesions with reported in-breast location, $57(81.4 \%)$ relapsed in the original tumor location.

Discussion: Although meta-analysis was not conducted, present analysis demonstrated that most local recurrences after skin-sparing or nipple-sparing mastectomy occurred within the skin or subcutaneous tissues. It was found that the original tumor location was the most frequent site of relapse. Therefore, special attention should be paid to the original tumor overlying the skin while planning postmastectomy radiation therapy.

Keywords! Breast neoplasm; mastectomy; breast implants; breast reconstruction

Submitted Jan 08, 2021. Accepted for publication May 14, 2021.

doi: 10.21037 /gs-21-15

View this article at: https://dx.doi.org/10.21037/gs-21-15

\footnotetext{
^ ORCID: 0000-0001-9275-3197.
} 


\section{Introduction}

Skin-sparing mastectomy (SSM) and nipple-sparing mastectomy (NSM) remove total breast tissue while preserving the skin envelope and inframammary ridge, or nipple-areolar complex (NAC). These conservative mastectomies have been increasingly used recently, as they improve cosmetic outcomes and enable immediate breast reconstruction $(1,2)$. The rates of reconstruction, as a surgical treatment for early breast cancer patients, are also increasing $(3,4)$. The risk of locoregional recurrence is related to a number of factors, including nodal status, lymphovascular invasion, tumor size, grade, and margin status (5-7). Although lacking supporting evidence, for women with a positive or close resection margin, chest wall irradiation is practically recommended (7). In the past, postmastectomy radiation therapy (PMRT) was only indicated to patients with advanced breast cancer but recently, indications have been expanded to recommend PMRT for patients with T1-2 breast cancer with one to three positive axillary nodes (8). This recommendation was party based on the Early Breast Cancer Trialists' Collaborative Group meta-analysis, which showed an overall survival benefit of PMRT in patients with $\mathrm{pN} 1 \mathrm{a}$ disease, as well as on the more recent data from the European Organization for Research and Treatment of Cancer 22922 trial, which demonstrated a survival benefit of regional nodal irradiation in early-stage breast cancer patients $(9,10)$.

Some studies reported that PMRT after reconstruction modestly increased the complication rate. Complications included capsular contractures and infection, which can eventually result in implant failure (11). On analyzing 15,000 mastectomy cases for complications from radiation therapy (RT), RT was found to be associated with an increased risk of implant removal in women who underwent implant-based reconstruction and fat necrosis in women who underwent autologous reconstruction $(12,13)$. Additionally, salvage treatment is challenging in the case of local recurrence (LR) in irradiated patients. Usually, in such cases, repeat chest wall irradiation is used because local control with repeat surgery alone remains unacceptable, with a 5 -year local control rate of only $33 \%$ (14). Repeat RT results in a feasible but modest increase in late toxicity, including grade $3-4$ fibrosis and lymphedema $(15,16)$. It is of utmost importance to fully understand and cover highrisk areas during initial breast cancer treatment to prevent re-irradiation.
The current PMRT target is based on a tangential field such that it includes the entire reconstructed autologous tissue or prosthesis. The use of modern volume-based RT planning may achieve the target volume dose while excluding normal tissues and thereby, reducing toxicity (17). In 2019, European Society for Radiotherapy and Oncology (ESTRO) set new delineation guidelines for the clinical target volume (CTV) for PMRT in the setting of breast reconstruction (18). This introduced different targets according to the location of residual breast tissue based on the reconstruction method.

This study aimed to localize LRs after mastectomy and reconstruction in patients with breast cancer. We tried to describe LR patterns between mastectomy and reconstruction types and find its implication for PMRT technique. We present the following article in accordance with the PRISMA reporting checklist (available at https:// dx.doi.org/10.21037/gs-21-15).

\section{Methods}

For the purpose of this review, a search for papers reporting the local control rate and the location of LRs after mastectomy and reconstruction was performed. Studies were identified using the Preferred Reporting Items for Systematic Reviews and Meta-Analyses (PRISMA) guidelines (19). The MEDLINE/PubMed and the Cochrane Centre Register of Controlled Trials (CENTRAL) were searched to identify publications with the following terms in the title or abstract: $(((($ Breast Neoplasms[MeSH Terms]) OR (Breast Cancer[Title/ Abstract]) OR (Breast Carcinoma[Title/Abstract]) OR (Breast Tumors[Title/Abstract]) OR (Cancer of Breast[Title/Abstract]) OR (Neoplasms, Breast[Title/ Abstract]) OR (Tumors, Breast[Title/Abstract]))) AND (((Mastectomy[MeSH Terms]) AND ((Breast Implants[MeSH Terms]) OR (Implants, Breast[Title/ Abstract]) OR (Breast Reconstruction[MeSH Terms]) OR (Mammoplasty[Title/Abstract])))) AND (((Neoplasm Recurrence, Local[MeSH Terms]) OR (Local Neoplasm Recurrence*[Title/Abstract]) OR (Locoregional Neoplasm Recurrence[Title/Abstract]) OR (Neoplasm Recurrence, Locoregional[Title/Abstract]) OR (Neoplasm Recurrences, Local[Title/Abstract]) OR (Recurrence*, Local Neoplasm[Title/Abstract]) OR (Recurrence*, Locoregional Neoplasm[Title/Abstract]))))).

The search was conducted in November 2020 and was filtered for "English language" and "Human" studies 


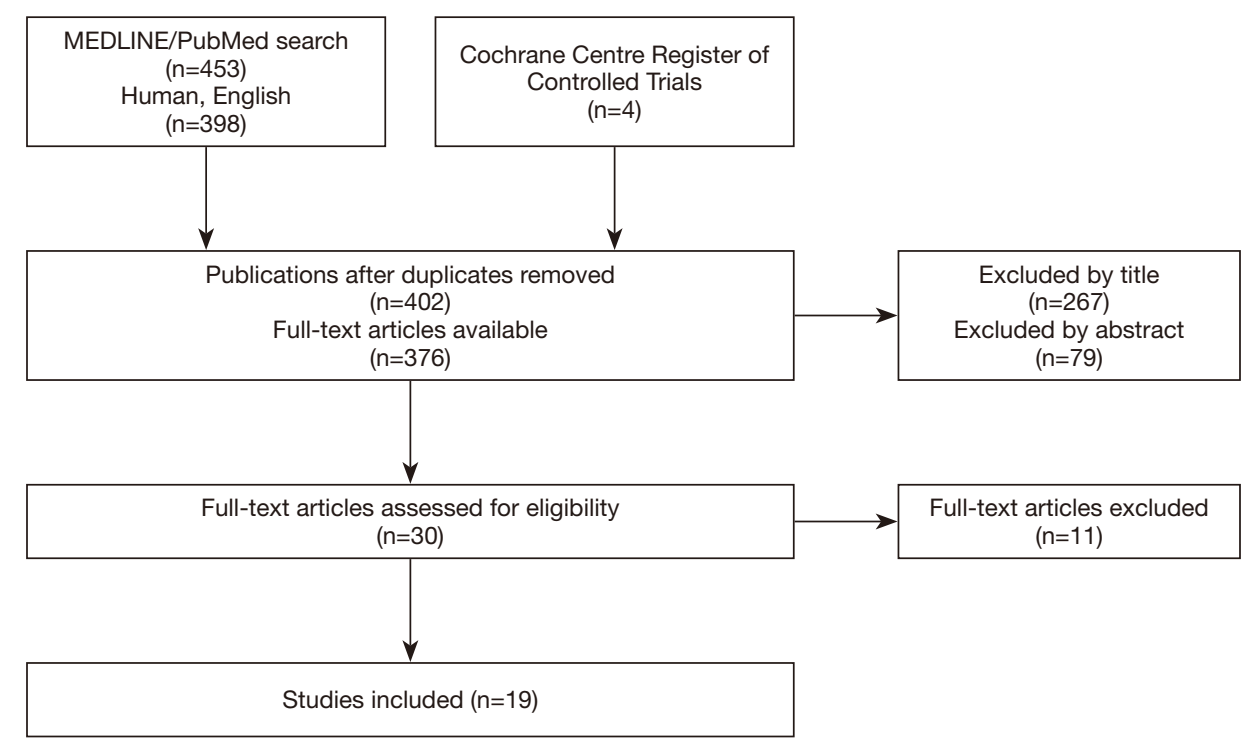

Figure 1 Pattern of local recurrence after mastectomy and reconstruction: PRISMA flow diagram. PRISMA, preferred reporting items for systematic reviews and meta-analyses.

only. No limitations were set for the year of publication or the type of study (retrospective or prospective). Only publications that included SSM or NSM followed by breast reconstruction and described the location of LR according to the surgery type were analyzed. Studies with full text available for further evaluation were included. Studies were selected based on the following inclusion criteria: reports on adult females undergoing mastectomy for breast cancer, more than 20 patients reported, reports on the type of mastectomy and reconstruction, reports on oncologic outcomes, reports on locations of LR, and reports available in English. Studies were excluded by any one of the following criteria: salvage mastectomy, prophylactic mastectomy, partial mastectomy, unclear distinction between local and regional recurrence, rare tumor types, neoadjuvant RT, and case reports or review papers or metaanalysis.

Mastectomies were indicated as NSM or SSM. Types of reconstruction included implant-reconstruction or autologous tissue reconstruction. Tissue expanders were often classified according to the reconstruction that was subsequently replaced. LR locations were indicated as skin and/or subcutaneous tissues, chest wall, or NAC, or the location was divided into breast quadrants.

Data were extracted and recorded in an Excel file with the following information: publication details (study design, published year); patient population (number of patients/ breasts, age, treated period, follow-up period); disease factors (histology, stage, resection margin); mastectomy; reconstruction; adjuvant RT; time of LR; location of LR (substructure, quadrant).

\section{Results}

A total of 457 publications were identified through PubMed and CENTRAL search using the keywords, of which 19 were eligible for inclusion in the final analysis (20-38). The PRISMA flow chart is presented in Figure 1. A summary of the included 19 studies is presented in Table 1. Of these, 17 studies were retrospective and two were prospective. The year of publication ranged from 1997 to 2019, with treatment period from 1973 to 2017. Totally, 4,787 patients and 5,764 treated breasts were included. Only therapeutic mastectomy cases were included for this analysis, of which $82.3 \%$ were for invasive carcinoma. In nine studies, stages $0-\mathrm{I}$, II, and III were reported in $51.7 \%, 38.9 \%$, and $9.4 \%$ of the cases, respectively $(21,24,25,27,29,31,33,35,36)$. In five studies that reported T-stage, T1, T2, and T3 tumors were in $60.2 \%, 35.2 \%$, and $4.4 \%$ of the cases, respectively $(22,26,28,37,38) . \mathrm{N} 0, \mathrm{~N} 1$, and $\mathrm{N} 2$ disease was reported in $65.1 \%, 24.8 \%$, and $10 \%$ of the patients, respectively $(26,28,37,38)$. In three studies that reported margin status, margin positivity was in $8.0 \%(24,26,34)$. Mean age of the patients was 46.7 years. Overall, adjuvant RT was used 
Table 1 Characteristics of the studies

\begin{tabular}{|c|c|c|c|c|c|c|c|}
\hline First author (year) & Patient/breast & Period & IDC & RT (\%) & Surgery & $\mathrm{N}$ & LR (\%) \\
\hline Balci (2019) & 193/193 & 2007-2017 & 51 & $50(25.9)$ & NSM + implant & 193 & $9(4.7)$ \\
\hline \multirow[t]{2}{*}{ Lee (2018) } & $1,032 / 1,032$ & 1993-2008 & Unknown & $87(8.4)$ & SSM + autologous & 694 & $35(3.4)$ \\
\hline & & & & & NSM + autologous & 338 & \\
\hline Chan (2018) & & & & & $\mathrm{NSM}+$ implant & 42 & \\
\hline Cont (2017) & $518 / 518$ & 2010-2015 & 461 & $94(18.1)$ & NSM + implant & 518 & $14(2.7)$ \\
\hline Agusti (2016) & $171 / 171$ & $1997-2010$ & 102 & $48(28.1)$ & SSM + implant & 171 & $11(6.4)$ \\
\hline Frey (2016) & $118 / 118$ & 2006-2014 & 74 & $15(12.7)$ & NSM + implant & 118 & $1(0.8)$ \\
\hline \multirow{2}{*}{ Stanec (2014) } & & & & & $\mathrm{NSM}+$ autologous & & \\
\hline & & & & & NSM + implant & & \\
\hline \multirow[t]{2}{*}{ Patterson (2012) } & $390 / 390$ & 1998-2008 & 244 & $40(10.3)$ & $\mathrm{TM}+$ autologous & 220 & $9(2.3)$ \\
\hline & & & & & SSM + autologous & 170 & \\
\hline \multirow[t]{2}{*}{ Reddy (2011) } & $494 / 494$ & 1999-2006 & 0 & $135(27.3)$ & mastectomy + autologous & 407 & $6(1.2)$ \\
\hline & & & & & mastectomy + implant & 87 & \\
\hline McCarthy (2008) & $309 / 309$ & 1995-1999 & 0 & $67(21.7)$ & mastectomy + implant & 309 & $12(3.9)$ \\
\hline Vaughan (2007) & $206 / 210$ & 1999-2006 & Unknown & $42(20.0)$ & SSM + autologous & 112 & $11(5.2)$ \\
\hline Snoj (2007) & & & & & SSM + autologous & 25 & \\
\hline \multirow[t]{2}{*}{ Mosahebi (2006) } & $71 / 71$ & - & 39 & $20(28.2)$ & NSM + autologous & 59 & $3(4.2)$ \\
\hline & & & & & $\mathrm{NSM}+$ implant & 12 & \\
\hline \multirow[t]{2}{*}{ Petit (2006) } & $102 / 106$ & 2002-2003 & 66 & $106(100.0)$ & $\mathrm{NSM}+$ autologous & 2 & $1(0.9)$ \\
\hline & & & & & NSM + implant & 104 & \\
\hline \multirow[t]{2}{*}{ Gerber (2003) } & $112 / 112$ & $1994-2000$ & Unknown & $31(27.7)$ & SSM + autologous & 51 & $6(5.4)$ \\
\hline & & & & & $\mathrm{NSM}+$ autologous & 61 & \\
\hline Cheung (1997) & $101 / 101$ & 1973-1979 & Unknown & $0(0,0)$ & NSM + implant & 101 & $16(15.8)$ \\
\hline
\end{tabular}

IDC, invasive ductal carcinoma; RT, radiation therapy; LR, local recurrence; NSM, nipple sparing mastectomy; SSM, skin sparing mastectomy; TM, total mastectomy; N, number. 
in $24.8 \%$, ranging $8.4-100 \%$. Comparison of treatment outcomes was not possible because the included studies were heterogeneous in the primary study aim, tumor stage, and treatment interventions. Consequently, data are presented using descriptive statistics.

Totally, 272 patients had a LR at 5,764 mastectomy sites, with the median time to LR ranging between 13.2 38 months. The reported rates of LR in the included studies ranged from $0.6 \%$ to $15.8 \%$, with the pooled estimate of the rate of recurrence at $4.7 \%$. An exceptionally high recurrence rate of $15 \%$ was seen in two studies $(20,28)$. Benediktsson $e t$ al. performed a retrospective review on NSM and implant reconstructions. Only multifocal or large tumors that were not suitable for partial mastectomy were included in this study (28). In another study that reviewed 134 subcutaneous mastectomy cases, there was insufficient information to determine if they had patients in the higher baseline risks; however, the treatment period was in 1970s (20). Excluding these papers, the overall LR rate was $4 \%$. In one paper, the recurrence site was classified as skin + chest wall versus NAC, and this study was excluded from further analysis (37). The recurrent sites were skin/ subcutaneous in 144 patients $(75.8 \%)$, chest wall in 27 (14.2\%), and NAC in 19 (10\%).

Of the total, 14 studies were analyzed according to mastectomy types (20,22-26,28,31-36,38). A total of 1,355 SSM patients were included, of whom 49 had LRs, and the LR rate was 3.5\%. Locations of LRs were skin/ subcutaneous tissues in $37(2.7 \%)$ and chest wall in 12 (0.9\%) patients (24-26,31,32,35). Additionally, 108 LR lesions were included in the 2,010 NSM patients, with LR rate of $5.2 \%$. Recurrent sites were skin/subcutaneous tissues in 83 patients $(4.1 \%), \mathrm{NAC}$ in $18(0.9 \%)$, and chest wall in $7(0.3 \%)(20,22,23,28,31,33-36,38)$. Totally, 14 studies were further analyzed according to the reconstruction type $(20,21,24,26-35,38)$. A total of 72 LR lesions were included in autologous tissue reconstruction (2.9\% in 2,465 patients) and $107 \mathrm{LR}$ lesions were in the implant reconstruction group (5.6\% in 1,917 patients). After autologous reconstruction, LRs were located in the skin in 45 patients $(1.8 \%)$, in the chest wall in $18(0.7 \%)$, and in the NAC in 9 (0.4\%) $(21,24,26,29-31,35)$. After implant reconstruction, sites included the skin in $91(4.7 \%)$, chest wall in $8(0.4 \%)$, and NAC in $8(0.4 \%)$ patients $(20,24,27-29,31-34,38)$. The LR locations according to mastectomy type (Table 2 ) and reconstruction type (Table 3) are summarized.

Seven studies reported the location of recurrent tumors, of which three indicated it in relation to the primary tumor site $(22,24,28)$, three indicated it as a breast quadrant $(21,23,33)$, and one indicated both (34). Of a total of $70 \mathrm{LR}$ lesions, $57(81.4 \%)$ relapsed in the same quadrant as the original tumor, $5(7.1 \%)$ were found in the upper breast, and $2(2.9 \%)$ were in the lower breast/inframammary fold. According to the reconstruction method, after autologous reconstruction, LR rate in the same quadrant, upper breast, and lower breast was $2.1 \%, 0.7 \%$, and $0.3 \%$, respectively, while, after implant reconstruction, it was $4.5 \%, 0.2 \%$, and $0.1 \%$, respectively.

\section{Discussion}

For all the 5,764 mastectomy sites, the LR rate was $4.7 \%$. Overall, skin and/or subcutaneous tissue recurrence was in $75.8 \%$, chest wall was in $14.2 \%$, and NAC was in $10 \%$ of the cases. Following SSM and NSM, LR rates were $3.5 \%$ and $5.2 \%$, respectively. According to reconstruction methods, LR rates of $2.9 \%$ and $5.6 \%$ were reported after autologous tissue and implant surgery, respectively. Between all mastectomies and reconstructions, skin and subcutaneous tissue was the most common site of LR occurrence (62.5$85 \%)$. Among the different breast quadrants, $81.4 \%$ of the LR lesions relapsed in the same quadrant as the primary lesion.

As predicted, most recurrences occurred in the skin or subcutaneous tissues. With the transition from traditional tangential field RT to three-dimensional planning, there has been a growing curiosity about which substructure is the focus of recurrence. Vargo et al. have published literature in this respect; upon investigating 278 postmastectomy relapsed patients with location information, they found that most recurrences were isolated within the skin and subcutaneous tissues $(72-100 \%)$ followed by the pectoralis muscle (39). The present study confirms that this pattern is the same when most of the overlying breast skin and NAC is preserved or reconstruction is accompanied. SSM and NSM accompanied by reconstruction are less invasive mastectomy that has not worsen oncologic outcome with superior cosmesis (40). However, there is a concern that the subcutaneous tissue left to maintain the viable skin flaps might be a source of breast cancer recurrence (41). This skin flap thickness is variable in different forms of mastectomy. Giannotti analyzed 501 postmastectomyreconstructed breast magnetic resonance imaging scans, to determine the frequency of residual breast tissue and thickness of the flap in patients with total mastectomy, SSM, and NSM. The results showed that residual breast 
Table 2 Sites of local recurrences after mastectomy

\begin{tabular}{|c|c|c|c|c|c|c|c|}
\hline Author & \multicolumn{4}{|c|}{ Nipple-sparing mastectomy } & \multicolumn{3}{|c|}{ Skin-sparing mastectomy } \\
\hline Balci & 193 & 6 & 0 & 3 & - & - & - \\
\hline Lee & 338 & 6 & 5 & 7 & 694 & 9 & 8 \\
\hline Chan & 97 & 1 & 1 & 1 & - & - & - \\
\hline Agusti & - & - & - & - & 171 & 8 & 3 \\
\hline Frey & 118 & 0 & 1 & 0 & - & - & - \\
\hline Stanec & 252 & 7 & 0 & 3 & 109 & 5 & 0 \\
\hline Vaughan & & & & & 210 & 10 & 1 \\
\hline Mosahebi & 71 & 2 & 0 & 1 & & - & - \\
\hline Petit & 106 & 1 & 0 & 0 & & - & - \\
\hline Cheung & 101 & 13 & 0 & 2 & & - & - \\
\hline Total (\%) & 2,010 & $83(4.1)$ & $7(0.3)$ & $18(0.9)$ & 1,355 & $37(2.7)$ & $12(0.9)$ \\
\hline
\end{tabular}

$\mathrm{N}$, number; NAC, nipple-areolar complex.

Table 3 Sites of local recurrences after mastectomy and reconstruction

\begin{tabular}{|c|c|c|c|c|c|c|c|c|}
\hline Author & \multicolumn{4}{|c|}{ Autologous reconstruction } & \multicolumn{4}{|c|}{ Implant reconstruction } \\
\hline Balci & - & - & - & - & 193 & 6 & 0 & 3 \\
\hline Lee & 1,032 & 15 & 13 & 7 & - & - & - & - \\
\hline Cont & - & - & - & - & 518 & 13 & 0 & 1 \\
\hline Frey & - & - & - & - & 118 & 0 & 1 & 0 \\
\hline Stanec & 255 & 8 & 0 & 1 & 106 & 4 & 0 & 2 \\
\hline Patterson & 390 & 9 & 0 & 0 & - & - & - & - \\
\hline Reddy & 407 & 3 & 2 & 0 & 87 & 0 & 1 & 0 \\
\hline Benediktsson & - & - & - & - & 216 & 34 & 0 & 0 \\
\hline Snoj & 157 & 1 & 0 & 0 & - & - & - & - \\
\hline Gerber & 112 & 3 & 2 & 1 & - & - & - & - \\
\hline Cheung & - & - & - & - & 101 & 13 & 0 & 2 \\
\hline Total (\%) & 2,465 & 45 (1.8) & $18(0.7)$ & $9(0.4)$ & 1,917 & $91(4.7)$ & $8(0.4)$ & $8(0.4)$ \\
\hline
\end{tabular}

$\mathrm{N}$, number; NAC, nipple-areolar complex. 
tissue was more frequently present after NSM, even after the exclusion of the NAC point $(2.8 \%$ for total mastectomy, $13.2 \%$ for SSM, and 51\% for NSM). Within the breast, the skin flap was thicker on the periphery than in the central regions. They did not find any significant difference in tumor recurrence in relation to the presence of residual breast tissue and flap thickness (42). Wiberg also demonstrated differences in skin flap thickness between the different breast quadrants, by analyzing 45 women who had undergone prophylactic mastectomy. However, there was not just one quadrant that significantly differed from the others, but pronounced differences were observed within several quadrants (43). There is no single recommended specific thickness for skin flap dissection. Superficial fascia can serve as a useful guide for limiting mammary tissue, but it is readily identified in just $56 \%$ of the patients (44). The flap thickness does not appear to be associated with obesity or age (41). Therefore, at the time of planning adjuvant RT, attention should be paid to the heterogeneous existence of residual subcutaneous tissues.

The probability of recurrence after SSM and NSM was higher in proximal to original tumor rather than confined to one specific quadrant. And this was consistent with the existing studies. In one of the included studies, Vaughan et al. investigated 210 SSM patients and reported that nine of 11 LRs occurred in the same quadrant as the original tumors and majority of the recurrences occurred in the subcutaneous tissues (24). Even after NSM, LRs almost invariably occurred in the subdermal tissue of the flap covering the area where the tumor was originally located (34). The feasibility of removing all uninvolved breast tissue and still leaving viable skin flaps, especially when the distance to the overlying dermis was too small, has been deemed negligible. A histologic study using 62 breast resection specimens revealed that in $50 \%$ of the specimens the minimal distance between the dermis and the breast tissue layer was $<1.1 \mathrm{~mm}$. A distance of $\geq 5 \mathrm{~mm}$, which is an acceptable threshold to prevent flap necrosis, was encountered in only $17 \%$ of the specimens (44). Consequently, patients undergoing SSM are reported to be at high risk for positive margins compared to simple mastectomy. Multiple ipsilateral tumors, and/or upper-inner quadrant disease increase the risk (45). Vaughan proposed to excise the skin and subcutaneous tissues overlying the primary tumor during the SSM procedure, as majority of the skin envelope would be spared and the inframammary fold would be intact, leading to an improved cosmetic outcome (24). It is clear that obtaining adequate margin is one of the most effective way to prevent recurrence at the original tumor site $(45,46)$. In the same context, boost dose RT might also be considered. Addition of scar boost dose following PMRT is still being used widely, especially in the presence of close (less than $2 \mathrm{~mm}$ ) or positive margins and for inflammatory breast cancer. When the decision to boost is made, a mastectomy scar to $10-16$ Gy in $5-8$ fractions is considered $(47,48)$. Since photons require tissue interaction to build up the dose, the dose at the skin surface is lower than the dose at the target. A $5-10 \mathrm{~mm}$ tissue-equivalent bolus may be placed on the chest wall to increase the skin dose for patients who have an increased risk of chest wall recurrence. The use of bolus in the PMRT setting to increase the dose to skin is still controversial, as its specific contribution for local control is unknown despite the known increased acute skin toxicity (49). Owing to the technical difficulties and concerns over capsular contracture or reconstructive failures, bolus is rarely applied after SSM or NSM. One method to potentially reduce the incidence of LRs would be to include the primary tumor site during scar boost dose or to apply tissue equivalent bolus to original tumor overlying the skin. This alteration in PMRT technique is also supported by the fact that majority of our LRs occurred in the subcutaneous tissues.

The advantage of subpectoral reconstruction over prepectoral reconstruction is the better cosmetic outcome and improved circulation of the skin flap, which lower the risk of necrosis. Subpectoral reconstruction causes capsular contracture in overwhelming proportion of patients, especially after PMRT (50). Animation deformity refers to the tethering of the skin flap to the underlying pectoralis major muscle, resulting in the patient's reconstructed surgical area being pulled, complaining of pain, and abnormal movement of the muscle $(51,52)$. The main advantages of prepectoral reconstruction are claimed to be avoidance of disruption of pectoralis major muscle and no animation deformity (53). These days, the use of acellular dermal matrix provides complete implant coverage, and it reported acceptable cosmetic results compared to subpectoral reconstruction (54). In the new ESTRO guideline, if sub-pectoral implant was used, the implant can be largely excluded because the clinical target volume (CTV)_chest wall does not include the deep dorsal pectoralis tissue. If reconstruction used a prepectoral positioned implant, the dorsal part between the implant and the pectoral muscle was recommended to be included only in case of the presence of adverse tumor factors. Adverse factors include large breast cancer, poor 
response to neoadjuvant systemic therapy, and chest wall invasion. Adjuvant RT-related late complications, including capsular contracture and failure of reconstruction, are expected to be decreased. The ESTRO guideline was predominately formulated based on expert opinions. The safety or risks about its clinical application have not been studied in prospective or even in retrospective studies. Ongoing trials, such as Primary Radiotherapy and DIEP flAp Reconstruction Trial (PRADA) (NCT02771938) or DBCG RT Recon Trial (NCT03730922) are evaluating the outcomes of PMRT combined with reconstruction. More studies are clearly needed to help reach a better international consensus for the PMRT CTV design. Through current study, meta-analysis was not conducted because the included studies were heterogeneous in the primary study aim, tumor stage, and treatment interventions.

In conclusion, consistent with total mastectomy studies, our analysis identified that most LRs after SSM or NSM occurred within the skin or subcutaneous tissues. Additionally, it was found that the original tumor location was the most frequently relapsed site. Therefore, special attention should be paid on the original tumor overlying the skin while planning PMRT, including boost dose or applying tissue-equivalent bolus.

\section{Acknowledgments}

Funding: This study was supported by a 2021 research grant from Pusan National University Yangsan Hospital.

\section{Footnote}

Reporting Checklist: The authors have completed the PRISMA reporting checklist. Available at https://dx.doi. org/10.21037/gs-21-15

Conflicts of Interest: All authors have completed the ICMJE uniform disclosure form (available at https://dx.doi. org/10.21037/gs-21-15). The authors have no conflicts of interest to declare.

Ethical Statement: The authors are accountable for all aspects of the work in ensuring that questions related to the accuracy or integrity of any part of the work are appropriately investigated and resolved.

Open Access Statement: This is an Open Access article distributed in accordance with the Creative Commons Attribution-NonCommercial-NoDerivs 4.0 International License (CC BY-NC-ND 4.0), which permits the noncommercial replication and distribution of the article with the strict proviso that no changes or edits are made and the original work is properly cited (including links to both the formal publication through the relevant DOI and the license). See: https://creativecommons.org/licenses/by-nc-nd/4.0/.

\section{References}

1. Agarwal S, Neumayer L, Agarwal JP. Therapeutic nipplesparing mastectomy: trends based on a national cancer database. Am J Surg 2014;208:93-8.

2. Wong SM, Chun YS, Sagara Y, et al. National Patterns of Breast Reconstruction and Nipple-Sparing Mastectomy for Breast Cancer, 2005-2015. Ann Surg Oncol 2019;26:3194-203.

3. Kim JW, Lee JH, Kim TG, et al. Breast reconstruction statistics in Korea from the Big Data Hub of the Health Insurance Review and Assessment Service. Arch Plast Surg 2018;45:441-8.

4. Yang RL, Newman AS, Lin IC, et al. Trends in immediate breast reconstruction across insurance groups after enactment of breast cancer legislation. Cancer 2013;119:2462-8.

5. Clarke M, Collins R, Darby S, et al. Effects of radiotherapy and of differences in the extent of surgery for early breast cancer on local recurrence and 15 -year survival: an overview of the randomised trials. Lancet 2005;366:2087-106.

6. Rowell NP. Radiotherapy to the chest wall following mastectomy for node-negative breast cancer: a systematic review. Radiother Oncol 2009;91:23-32.

7. Rowell NP. Are mastectomy resection margins of clinical relevance? A systematic review. Breast 2010;19:14-22.

8. Recht A, Comen EA, Fine RE, et al. Postmastectomy Radiotherapy: An American Society of Clinical Oncology, American Society for Radiation Oncology, and Society of Surgical Oncology Focused Guideline Update. Ann Surg Oncol 2017;24:38-51.

9. Poortmans PM, Collette S, Kirkove C, et al. Internal Mammary and Medial Supraclavicular Irradiation in Breast Cancer. N Engl J Med 2015;373:317-27.

10. Whelan TJ, Olivotto IA, Parulekar WR, et al. Regional Nodal Irradiation in Early-Stage Breast Cancer. N Engl J Med 2015;373:307-16.

11. Ho A, Cordeiro P, Disa J, et al. Long-term outcomes 
in breast cancer patients undergoing immediate 2-stage expander/implant reconstruction and postmastectomy radiation. Cancer 2012;118:2552-9.

12. Jagsi R, Jiang J, Momoh AO, et al. Complications After Mastectomy and Immediate Breast Reconstruction for Breast Cancer: A Claims-Based Analysis. Ann Surg 2016;263:219-27.

13. Jagsi R, Momoh AO, Qi J, et al. Impact of Radiotherapy on Complications and Patient-Reported Outcomes After Breast Reconstruction. J Natl Cancer Inst 2018;110:157-65.

14. Dahlstrøm KK, Andersson AP, Andersen M, et al. Wide local excision of recurrent breast cancer in the thoracic wall. Cancer 1993;72:774-7.

15. Wahl AO, Rademaker A, Kiel KD, et al. Multiinstitutional review of repeat irradiation of chest wall and breast for recurrent breast cancer. Int J Radiat Oncol Biol Phys 2008;70:477-84.

16. Müller AC, Eckert F, Heinrich V, et al. Re-surgery and chest wall re-irradiation for recurrent breast cancer: a second curative approach. BMC Cancer 2011;11:197.

17. Kaidar-Person O, Jones EL, Zagar TM. Team Work: Mastectomy, Reconstruction, and Radiation. Plast Reconstr Surg Glob Open 2017;5:e1385.

18. Kaidar-Person O, Vrou Offersen B, Hol S, et al. ESTRO ACROP consensus guideline for target volume delineation in the setting of postmastectomy radiation therapy after implant-based immediate reconstruction for early stage breast cancer. Radiother Oncol 2019;137:159-66.

19. Moher D, Liberati A, Tetzlaff J, et al. Preferred reporting items for systematic reviews and meta-analyses: the PRISMA statement. PLoS Med 2009;6:e1000097.

20. Cheung KL, Blamey RW, Robertson JF, et al. Subcutaneous mastectomy for primary breast cancer and ductal carcinoma in situ. Eur J Surg Oncol 1997;23:343-7.

21. Gerber B, Krause A, Reimer T, et al. Skin-sparing mastectomy with conservation of the nipple-areola complex and autologous reconstruction is an oncologically safe procedure. Ann Surg 2003;238:120-7.

22. Mosahebi A, Ramakrishnan V, Gittos M, et al. Envelope mastectomy and immediate reconstruction (EMIR), improving outcome without oncological compromise. J Plast Reconstr Aesthet Surg 2006;59:1025-30.

23. Petit JY, Veronesi U, Orecchia R, et al. Nipplesparing mastectomy in association with intra operative radiotherapy (ELIOT): A new type of mastectomy for breast cancer treatment. Breast Cancer Res Treat 2006;96:47-51.
24. Vaughan A, Dietz JR, Aft R, et al. Scientific Presentation Award. Patterns of local breast cancer recurrence after skin-sparing mastectomy and immediate breast reconstruction. Am J Surg 2007;194:438-43.

25. Meretoja TJ, von Smitten KA, Leidenius MH, et al. Local recurrence of stage 1 and 2 breast cancer after skin-sparing mastectomy and immediate breast reconstruction in a 15year series. Eur J Surg Oncol 2007;33:1142-5.

26. Snoj M, Arnez ZM, Sadikov A, et al. Breast reconstruction following mastectomy for invasive breast cancer by free flaps from the abdomen is oncologically safe. Eur J Surg Oncol 2007;33:541-5.

27. McCarthy CM, Pusic AL, Sclafani L, et al. Breast cancer recurrence following prosthetic, postmastectomy reconstruction: incidence, detection, and treatment. Plast Reconstr Surg 2008;121:381-8.

28. Benediktsson KP, Perbeck L. Survival in breast cancer after nipple-sparing subcutaneous mastectomy and immediate reconstruction with implants: a prospective trial with 13 years median follow-up in 216 patients. Eur J Surg Oncol 2008;34:143-8.

29. Reddy S, Colakoglu S, Curtis MS, et al. Breast cancer recurrence following postmastectomy reconstruction compared to mastectomy with no reconstruction. Ann Plast Surg 2011;66:466-71.

30. Patterson SG, Teller P, Iyengar R, et al. Locoregional recurrence after mastectomy with immediate transverse rectus abdominis myocutaneous (TRAM) flap reconstruction. Ann Surg Oncol 2012;19:2679-84.

31. Stanec Z, Zic R, Budi S, et al. Skin and nipple-areola complex sparing mastectomy in breast cancer patients: $15-$ year experience. Ann Plast Surg 2014;73:485-91.

32. Agusti A, Ward A, Montgomery C, et al. Aesthetic and oncologic outcomes after one-stage immediate breast reconstruction using a permanent biodimensional expandable implant. J Plast Reconstr Aesthet Surg 2016;69:211-20.

33. Frey JD, Alperovich M, Kim JC, et al. Oncologic outcomes after nipple-sparing mastectomy: A singleinstitution experience. J Surg Oncol 2016;113:8-11.

34. Cont NT, Maggiorotto F, Martincich L, et al. Primary tumor location predicts the site of local relapse after nipple-areola complex (NAC) sparing mastectomy. Breast Cancer Res Treat 2017;165:85-95.

35. Lee SB, Lee JW, Kim HJ, et al. Long-term outcomes of patients with breast cancer after nipple-sparing mastectomy/skin-sparing mastectomy followed by immediate transverse rectus abdominis musculocutaneous 
flap reconstruction: Comparison with conventional mastectomy in a single center study. Medicine (Baltimore) 2018;97:e0680.

36. Chan YH, Yau WM, Cheung PS. Oncological Safety and Technical Feasibility of Nipple-Sparing Mastectomy for Breast Cancer: The Hong Kong Experience. World J Surg 2018;42:1375-83.

37. Wu ZY, Kim HJ, Lee JW, et al. Breast Cancer Recurrence in the Nipple-Areola Complex After Nipple-Sparing Mastectomy With Immediate Breast Reconstruction for Invasive Breast Cancer. JAMA Surg 2019;154:1030-7.

38. Balci FL, Kara H, Dulgeroglu O, et al. Oncologic safety of nipple-sparing mastectomy in patients with short tumornipple distance. Breast J 2019;25:612-8.

39. Vargo JA, Beriwal S. RTOG Chest Wall Contouring Guidelines for Post-Mastectomy Radiation Therapy: Is It Evidence-Based? Int J Radiat Oncol Biol Phys 2015;93:266-7.

40. Lanitis S, Tekkis PP, Sgourakis G, et al. Comparison of skin-sparing mastectomy versus non-skin-sparing mastectomy for breast cancer: a meta-analysis of observational studies. Ann Surg 2010;251:632-9.

41. Robertson SA, Rusby JE, Cutress RI. Determinants of optimal mastectomy skin flap thickness. Br J Surg 2014;101:899-911.

42. Giannotti DG, Hanna SA, Cerri GG, et al. Analysis of Skin Flap Thickness and Residual Breast Tissue After Mastectomy. Int J Radiat Oncol Biol Phys 2018;102:82-91.

43. Wiberg R, Andersson MN, Svensson J, et al. Prophylactic Mastectomy: Postoperative Skin Flap Thickness Evaluated by MRT, Ultrasound and Clinical Examination. Ann Surg Oncol 2020;27:2221-8.

44. Beer GM, Varga Z, Budi S, et al. Incidence of the superficial fascia and its relevance in skin-sparing mastectomy. Cancer 2002;94:1619-25.

45. Sheikh F, Rebecca A, Pockaj B, et al. Inadequate margins

Cite this article as: Joo JH, Ki Y, Kim W, Nam J, Kim D, Park J, Kim HY, Jung YJ, Choo KS, Nam KJ, Nam SB. Pattern of local recurrence after mastectomy and reconstruction in breast cancer patients: a systematic review. Gland Surg 2021;10(6):20372046. doi: $10.21037 / g s-21-15$ of excision when undergoing mastectomy for breast cancer: which patients are at risk? Ann Surg Oncol 2011;18:952-6.

46. Cao D, Tsangaris TN, Kouprina N, et al. The superficial margin of the skin-sparing mastectomy for breast carcinoma: factors predicting involvement and efficacy of additional margin sampling. Ann Surg Oncol 2008; 15:1330-40.

47. Mayadev J, Fish K, Valicenti R, et al. Utilization and impact of a postmastectomy radiation boost for invasive breast cancer. Pract Radiat Oncol 2014;4:e269-78.

48. Remick J, Amin NP. Postmastectomy Breast Cancer Radiation Therapy. Treasure Island (FL): StatPearls Publishing, 2020.

49. Pignol JP, Vu TT, Mitera G, et al. Prospective evaluation of severe skin toxicity and pain during postmastectomy radiation therapy. Int J Radiat Oncol Biol Phys 2015;91:157-64.

50. Mioton LM, Gaido J, Small W Jr, et al. Differences in breast aesthetic outcomes due to radiation: A validated, quantitative analysis of expander-implant reconstruction. Can J Plast Surg 2013;21:73-7.

51. Becker H, Fregosi N. The Impact of Animation Deformity on Quality of Life in Post-Mastectomy Reconstruction Patients. Aesthet Surg J 2017;37:531-6.

52. Nigro LC, Blanchet NP. Animation Deformity in Postmastectomy Implant-Based Reconstruction. Plast Reconstr Surg Glob Open 2017;5:e1407.

53. Kobraei EM, Cauley R, Gadd M, et al. Avoiding Breast Animation Deformity with Pectoralis-Sparing Subcutaneous Direct-to-Implant Breast Reconstruction. Plast Reconstr Surg Glob Open 2016;4:e708.

54. Chandarana MN, Jafferbhoy S, Marla S, et al. Acellular dermal matrix in implant-based immediate breast reconstructions: a comparison of prepectoral and subpectoral approach. Gland Surg 2018;7:S64-9. 